\title{
A poligamia em Une si longue lettre e Niketche: uma história de poligamia
}

Resumo: $\mathrm{O}$ objetivo deste artigo é apresentar dois romances cuja temática comum é a poligamia. Ambos foram escritos por mulheres africanas de países diferentes e em diferentes épocas: Mariama Bâ, no Senegal e Paulina Chiziane, em Moçambique. Une si longue lettre, de Mariama Bâ, foi publicado pela primeira vez em 1979 e é inédito em Português. Niketche: uma história de poligamia, de Paulina Chiziane, foi publicado pela primeira vez em 2002. O objetivo desta análise será colocar em relevo a continuidade temática dos dois romances. De fato, ambos os textos têm por foco mulheres que vivem a poligamia em diferentes países africanos e sob diferentes formações culturais.

Palavras-chave: Literatura Feminina - Literatura Africana - Poligamia Patriarcado - Feminismo

Résumé: L'objectif de cet article est présenter deux romans dont la thématique commune est la polygamie. Les deux ouvrages ont été écrits par des femmes de différents pays et de différents époques: Mariama Bâ, du Sénégal et Paulina Chiziane, du Mozambique. Une si longue lettre, de Mariama Bâ,

Marina Bueno de Carvalho é graduada e licenciada em Língua Portuguesa pela Universidade de São Paulo. Trabalha como editora e revisora de livros didáticos no mercado editorial. Atualmente, é professora de Português e Francês, além de tradutora de Une si longue lettre, de Mariama Bâ. Rua Mateus Grou, 502 apartamento 63 - CEP: 05415-040 - Jardim Europa, São Paulo - Capital. E-mail: buenomarina541@ gmail.com 
a été publié la première fois em 1979 et ce Roman n'a pas encore de tradution en portugais. La deuxième ouvrage a être abordé et publié la première fois en 2002, est Niketche: uma história de poligamia, de Paulina Chiziane. Le propôs de l'analyse sera de mettre en relief la continuité témathique entre ces deux romans. En effet, tous deux se focalisent sur lês femmes vivant la polygamie dans divers pays africains et dans une pluralité de cultures.

Keywords: Female Literature - African Literature - Polygamy - Patriarchate - Feminism

Mariama Bâ nasceu em Dakar, em 1929. Era filha do primeiro Ministro da Saúde do Senegal e foi encorajada pelo pai a continuar seus estudos, situação rara para uma mulher senegalesa nascida em uma família muçulmana, na época. A autora tornou-se professora em 1947, profissão que exerceu por doze anos e da qual se afastou por problemas de saúde. Mariama Bâ se casou e foi mãe de nove crianças, divorciou-se e casou-se novamente. Começou a escrever tardiamente e apenas o romance tratado neste artigo foi publicado em vida. Seu segundo romance, Un chant écarlate, foi publicado postumamente, em 1981, ano de sua morte, aos 52 anos.

Une si longue lettre foi organizado em forma epistolar. $\mathrm{O}$ romance é formado pela reunião de cartas de Ramatoulaye à Aïssatou durante o período de reclusão pela morte de seu marido. Ä̈ssatou é sua amiga desde a infância e nestas cartas são confidenciadas suas impressões sobre os rituais pelos quais passa durante a reclusão de três meses e dez dias. Neste momento, faz um balanço de sua vida.

Essa estrutura organizacional do romance provoca no leitor a impressão de violar uma carta e descobrir o relato emocionado de uma mulher madura, mãe de doze filhos e viúva de um casamento poligâmico. Nesta carta, será relatada sua vida e seu cotidiano, permeado de memórias como a infância, o namoro, o casamento contra a vontade de sua família, e que após anos de convívio torna-se poligâmico sem seu conhecimento, a morte do marido, a partilha dos bens. Todos esses momentos são relatados minuciosamente revelando a cultura senegalesa e o esforço de uma mulher desta sociedade para emancipar-se vinte anos após a independência do Senegal. 
MARINA BUENO DE CARVALHO A poligamia em Une si longue lettre e Niketche: uma história de poligamia

O segundo romance abordado neste artigo, Niketche: uma história de poligamia, também há em detalhes a trajetória de uma mulher que passa pelo levirato ${ }^{2}$, pela suposta morte de seu marido. Em Niketche: uma história de poligamia, Rami descobre que seu marido tem cinco outras mulheres com as quais tem, ao todo, 16 filhos. Tratadas como amantes por seu marido, Rami faz um trabalho intenso para inserir essas mulheres na família e dar-lhes empregabilidade. No início, as amantes de seu marido tratam-na mal, mas após várias entrevistas aceitam por organizarem-se e exigir de Tony a legalidade dos relacionamentos, passando pelo lovolo ${ }^{3}$ e reconhecimento da paternidade das crianças. Um aspecto deste romance é a consciência de Rami sobre a importância da independência financeira feminina. De fato, ela empresta dinheiro às suas rivais ${ }^{4}$, faz-lhes estudarem para aprender uma profissão ou abrir um pequeno negócio para que pudessem sustentar a família. Tony é descrito como um sedutor incorrigível que acaba por tornar-se vítima de seus impulsos. Ao final do romance, Tony termina sozinho: todas as suas mulheres acabam por entrar em novos relacionamentos e ele é abandonado, inclusive por Rami, que acaba por se casar com o cunhado por engravidar no levirato, o kutchinga, realizado por darem seu marido por morto, sendo que na realidade ele fazia uma viagem secreta para França com uma sexta mulher.

Em ambos os romances são relatadas as experiências de mulheres que vivem a poligamia e o esforço que fazem para emancipar-se desta realidade. Se em Une si longue lettre é relatada a dor dessa primeira-esposa abandonada pelo marido, que depois de cinco anos torna-se viúva e, no momento do inventário, descobre que sua casa foi hipotecada para que realizassem o segundo casamento. Já em Niketche, essa primeira-esposa une-se às suas rivais e elabora, seguindo as regras previstas para o casamento poligâmico em Moçambique, sua revanche contra o marido, que acaba por perder a liberdade de relacionar-se com diversas mulheres extraconjugalmente.

2 Levirato é quando uma esposa viúva deve casar-se com o irmão do falecido marido, ou seja, cunhado.

3 Lovolo: ou "A festa do lovolo". Festa em que tradicionalmente os parentes da noiva serviam cerveja e enxadas aos parentes do noivo. A descrição do lovolo está em Usos e Costumes dos Bantu, de Henri Junod, p.114.

4 Nas sociedades retratadas nos romances analisados neste artigo, as personagens representadas pelas esposas não são amigas, mas tratadas como rivais. Sobre a rivalidade entre esposas em casamentos poligâmicos, há o estudo La femme de mon mari: Anthropologie du mariage polygamique en Afrique et en France, de Sylvie Fainzang e Odile Journet. 
Ao longo de Niketche, a protagonista confidencia-se com o espelho. Em Une si longue lettre, a protagonista, como dito anteriormente, confidencia-se com a amiga de infância, por meio de cartas.

Entre os romances, salvo as grandes diferenças entre povos, geografias e colonizações, parece haver uma continuidade entre vozes femininas tentando reagir frente à dominação do sexo masculino. Os romances são realistas e representam as sociedades nas quais foram produzidos. Em ambas sociedades, as esposas não herdam de seu marido ou de seu pai e seus acessos aos bens materiais e de sustento são mediados pelo casamento ${ }^{5}$, sendo autorizado o uso da terra para o trabalho, mas não sua posse.

Como relata o texto Nosso corpo, nossa saúde: a saúde e a sexualidade das mulheres em África Subsaariana (Notre corps, notre santé: la santé et la sexualité des femmes en Afrique subsaharienne), organizado por Fatou Sow e Codou Bop sobre a saúde física e sexual da mulher subsaariana, o aspecto socioeconômico seria fundamental para a influência de doenças às quais a mulher está exposta, assim como estão sujeitas ao alto índice de natalidade e o alto número de mortes provocadas pelos partos.

Esta obra é iniciada pela descrição do patriarcalismo e sua influência na saúde feminina. Neste trecho selecionado, o patriarcalismo é descrito com disseminado não apenas em África, mas em todo mundo:

A dominação masculina refere-se à uma ideologia (preponderância do pai ou do marido no sistema patriarcal/posição também preponderante do tio ou do irmão no sistema matriarcal). Ela repousa sobre a subordinação das mulheres à ordem social que faz do homem o chefe da família. A dominação masculina se estabelece no quadro de suas relações desiguais e encontra-se em todas as culturas africanas como na maioria das culturas em escala mundial. ${ }^{6}$ (SOW, F.; BOP, C., 2004, p. 15)

\footnotetext{
5 Sobre esse assunto consultar "Práticas tradicionais de casamento". Compêndio de estudos de países sobre gênero e terra. Disponível na internet no endereço: < http://www.fao.org/docrep/010/a0297p/ a0297p00.htm > . Esse texto tratará do acesso das mulheres africanas à terra e do direito à herança.

6 No original: La domination masculine fait référence à une idéologie culturelle (prépondérance du père ou du mari dans l'ideologie patriarcale / position tout aussi prépondérante de l'oncle ou du frère dans le système matriarcal). Elle repose sur la subordination des femmes à l'ordre social qui fait de l'homme le chef de la famille. La domination masculine s'établit dans le cadre de ces rapports inégaux et se retrouve pratiquement dans toutes les cultures africaines, comme dans la majorité des cultures à l'échelle mondiale
} 
MARINA BUENO DE CARVALHO A poligamia em Une si longue lettre e Niketche: uma história de poligamia

Em Família e lei no Senegal: permanências e mudanças (Famille et loi au Senegal: permanences et changements), Fatou Sow explica que a família senegalesa é organizada pelas sobreposições da cultura berbere, da religião muçulmana e da cultura ocidental trazida e imposta pela colonização do território pela França. No trecho selecionado, a autora identifica o patriarca com poderes religiosos, sociais e econômicos sobre a família/concessão. Cito:

O poder familiar é exercido pelo homem: o pai, o tio, o marido ou pelo irmão
mais velho. Esse patriarca real ou simbólico é, em geral, o homem mais velho
da família seja ele de parte materna ou paterna. Na família rural estendida,
ele é o chefe da célula produtiva. Seu status social é ligado à potência econô-
mica. Ele gere as terras da família estendida, assim como o produto destas ter-
ras. Ele decide em todas as questões importantes, o casamento, o divórcio, a
divisão de herança, a venda de bens, etc. [...] nas comunidades muçulmanas,
o patriarca dirige a vida religiosa da comunidade familiar estendida, seja ela
familiar ou biológica. Sua autoridade parece incontestável, ela é apenas, em
realidade, obediente às regras sociais dominantes que delimitam seu campo de
ação

Por esse trecho, pode-se identificar a imagem do patriarca como possuidor de poder na célula familiar superior à feminina. Seus poderes expandem-se externamente e internamente à concessão; é religioso e econômico. É importante mencionar que a família senegalesa é diferente na célula familiar ocidental. Lá, a família é estendida e circunscrevem-se tios, sobrinhos e avós. $\mathrm{Na}$ organização da casa, todos vivem juntos em uma concessão, terreno dividido em pequenas partes formada por casas de tamanhos diferentes, segundo a necessidade de cada pequeno grupo familiar. A concessão é administrada pelo patriarca, homem mais velho da família que detém os poderes de decisão em situações importantes.

\footnotetext{
7 No original: Le pouvoir familial est exercé par l'homme: le père, l'oncle, le mari ou l'aîné des frères. Ce patriarche réel ou symbolique est en général l'homme le plus âgé de la famille, qu'il soit de la lignée maternelle ou de la lignée paternelle. Dans la famille rurale étendue, Il est le chefe de la cellule de prodution. Son statut social y est lié à sa puissance économique. Il gère les terres de la famille étendue, ainsi que les produits de cette terre. Il peut trancher sur toutes les questions importantes, dont le mariage, le divorce, le partage de l'heritage, la vente de biens foncier, etc. [...] dans les communautés musulmanes, le patriarche dirige la vie religieuse de la communauté familiale sociele et biologique étendue. Bien que son autorité semble incontestée, elle ne l'est en réalité que si lui-même obéit aux règle sociales dominantes qui délimitent son champ d'action.
} 
$\mathrm{Na}$ sociedade patriarcal, a função principal que as mulheres terão na família é relacionada ao trabalho e à maternidade. Nas sociedades poligâmicas, a mulher deve total fidelidade ao marido e ele exige certeza que os filhos sucessores sejam seus biologicamente. A mulher seria reduzida à função materna e, consequentemente, seria reificada. Esse tema é abordado e analisado por Simone de Beauvoir em O Segundo Sexo. Cito:

\begin{abstract}
(...) Particularmente, quando se torna proprietário do solo, é que reivindica também a propriedade da mulher. [...] Quer que o trabalho familiar que utiliza em proveito de seus campos seja totalmente seu e, para isso, é preciso que os trabalhadores lhe pertençam: escraviza a mulher e os filhos. Precisa de herdeiros através dos quais se prolongará sua vida terrestre - pelo fato de lhes legar seus bens - e que lhe renderão, além-túmulo, as honras necessárias ao repouso de sua alma. [...] Não há, nos tempos primitivos, revolução ideológica mais importante do que a que substitui pela agnação a filiação uterina; a partir de então a mãe é relegada à função de ama, de serva, e a soberania do pai é exaltada: ele é que detém os direitos e os transmite (BEAUVOIR, 1970, p.99) [grifos do autor].
\end{abstract}

Na perspectiva de Beauvoir (1970), a mulher teria passado a ser propriedade masculina no mesmo movimento em que o homem criou a propriedade privada e a descoberta da contribuição masculina para a concepção. Nesse momento, a mulher passaria a ser considerada "serva" e não companheira. Essa soberania masculina deve-se à invenção da propriedade privada e à ideia de hereditariedade.

Tanto em Une si longue lettre quanto em Niketche: uma história de poligamia as personagens representadas pelos maridos são figuras do patriarca. Mais jovens que um ancião, entretanto, os filhos mais velhos de suas famílias, são bem-sucedidos profissionalmente. Ambos os personagens representam a ordem instituída. Em Niketche, o marido de Rami é chefe de polícia. Em Une si longue lettre, o marido de Ramatoulaye é advogado.

Em Une si longue lettre, o patriarca advogado falece inesperadamente de um ataque cardíaco. Essa é uma imagem simbólica muito forte: um patriarca que tem como função social interpretar a lei que sofre de parada cardíaca. Sua esposa poderá escolher entre continuar participando do núcleo familiar do marido e passar pelos rituais previstos pela religião muçulmana ou poderá negar-se a cumpri-los e ser excluída do círculo familiar. O romance tratará do 
MARINA BUENO DE CARVALHO A poligamia em Une si longue lettre e Niketche: uma história de poligamia

percurso de uma mulher bastante religiosa que cumpre quase todos os rituais previstos pela tradição muçulmana, mas nega-se a casar-se com o herdeiro de seu marido ou com um antigo pretendente. Sua solução é radical: a viúva assume os cuidados dos doze filhos com a ajuda de sua filha mais velha, sem casar-se novamente.

Como dito anteriormente, na sociedade senegalesa representada em Une si longue lettre, as primeiras-esposas viúvas não herdam os bens materiais de seus maridos. Os bens materiais são herdados pela família do falecido. Outro agravante da situação financeira da personagem principal é que sua casa foi hipotecada para pagar a nova casa de sua co-esposa, ou rival. Ou seja, ela vê-se abandonada e sem nenhum recurso, salvo a presença de seus filhos e de sua amiga, Aïssatou. De fato, Ramatoulaye não herda, mas a segunda-esposa herda o que ganhou em vida por doação do falecido pelo casamento: quase todo o acúmulo do casal durante 30 anos. Nesses casos, a viúva ver-se-ia obrigada a casar-se novamente para ter acesso à terra ${ }^{8} \mathrm{e}$ à possibilidade de subsistência.

Em Família e lei no Senegal (Famille et loi au Sénégal), Fatou Sow explica a organização social senegalesa e a transmissão dos bens materiais:

Uma viúva sem filhos é praticamente excluída da partilha de seu marido falecido. Sob o regime de regras de costumes a viúva com ou sem filhos não herdará jamais de seu falecido marido, cujos bens vão para um irmão ou a outro parente sanguíneo. ${ }^{9}$ (SOW, 1996, p.136).

Niketche: uma história de poligamia é próximo. O patriarca é chefe de polícia, ou seja, também uma profissão que representa a ordem. Em determinado momento da narrativa, a família de Tony acredita-o morto e a protagonista enviúva e passa por todo o ritual de viuvez. Também perde todos os bens materiais, como casa e móveis, e passa pelo levirato, o chamado kutchingar para os moçambicanos.

8 O acesso à terra é uma das pautas do movimento feminista de algumas regiões africanas, como Senegal e Burkina-Faso. Outras pautas do movimento feminista senegalês são o fim da excisão feminina, o fim do casamento precoce e direito à herança. Como informou a Ministra da Saúde do Senegal, Awa Maria Coll Seck, no encontro promovido pelo jornal Le Monde, em Paris, em março de 2016, a lei de direito à herança estava sendo discutida naquele momento no Congresso Senegalês.

$9 \quad$ No original: Une veuve sans enfant est pratiquement exclue de la propriété de son défunt mari. Sous le régime des règle coutumières, une veuve avec ou sans enfant, n'héritais jamais de son défunt mari dont les biens allaient à un frère ou à tout autre parent par le sang 


\section{Cito o trecho:}

Depois do funeral, a divisão de bens. Carregam tudo o que podem: geladeira, cama, pratos, mobília, cortinado. Até as peúgas e cuecas do Tony disputaram. Levaram quadros, tapetes da cama de banho. Deixaram-me as paredes e o teto, e dão-me um prazo de trinta dias para abandonar a casa. Pilharam a mim, só a mim (CHIZIANE, 2002, p. 220).

E num trecho um pouco à frente:

Sinto alguma coisa quente no meu ombro. É uma mão. Um braço. Sinto o cheiro de homem. Uma corda arrebata-me pela cintura. É o outro braço que me enlaça, que me rapta. Chegou a hora do kutchinga, a tradição entrega-me nos braços do herdeiro. Por que não me disseram elas que era hoje? Para quê todo este segredo, esta surpresa? Não tenho nada do meu ser. Nem desejo, nem sombra. Se eu recuso este ato me tiram tudo, até os filhos, e fico de mãos vazias. Nada deste mundo é meu e nem eu mesma me pertenço (CHIZIANE, 2002, p. 223).

É possível identificar o levirato como uma prática comum entre os Bantu, etnia majoritária de Moçambique, mas comum também entre os Peul, etnia dos personagens de Une si longue lettre, do Senegal. Em ambos os romances, o segundo-casamento acontece sem os consentimentos das primeiras-esposas. Elas passam, ou seria previsto que passassem, pelo levirato. Escritos em primeira-pessoa, nos dois romances há a representação de sociedades nas quais as esposas encontram-se em uma situação na qual não são consideradas na partilha dos bens, mas como parte dos bens. Seria a reificação, ou coisificação. Em Une si longue lettre, este conceito se repete duas vezes por meio da ação das personagens: a primeira no começo da narrativa, quando fazem o funeral na casa da primeira-esposa e quando fazem o "Mirasse", ou o inventário, na presença do Imam.

Sobre o levirato, na obra O Segundo Sexo, Simone de Beauvoir discorrerá sobre o papel do sexo feminino na sociedade Ocidental, entretanto, em alguns trechos a autora discorre sobre alguns costumes das mulheres do Oriente. Sobre o levirato, a autora expressa: 
MARINA BUENO DE CARVALHO A poligamia em Une si longue lettre e Niketche: uma história de poligamia

os regimes em que a mulher se acha sob tutela, um dos problemas que se põem é o da situação das viúvas. A solução mais radical consiste em sacrificá-las sobre o túmulo do marido. [...] É muito mais frequente que a mulher seja posta à disposição dos herdeiros do esposo. O levirato assume, por vezes, a forma da poliandria; para obviar às incertezas da viuvez, dão-se como maridos a uma mulher todos os irmãos de uma família, costume que serve também para defender a gens contra a possível impotência do marido (BEAUVOIR, 1970, p. 105-6, grifos do autor).

Talvez as questões das mulheres orientais não sejam tão distantes das mulheres ocidentais. Com roupagem diferente, o patriarcalismo continua ceifando a existência feminina independentemente de suas coordenadas geográficas.

Como dito anteriormente, Simone de Beauvoir trata do Ocidente, mas acompanha-se a influência de sua obra, O Segundo Sexo, na tecitura de Niketche: uma história de poligamia pela menção direta à ideia mais difundida pelo feminismo Ocidental.

- Então não és mulher - diz-me com desdém -, és ainda criança. Como queres tu ser feliz no casamento, se a vida a dois é feita de amor e sexo e nada te ensinaram sobre a matéria?

Olhei-a com surpresa. De repente lembro-me de uma frase famosa - ninguém nasce mulher, torna-se mulher. Onde terei eu ouvido esta frase? (CHIZIANE, 2002, p. 37)

No texto Niketche: o existencialismo no feminino, Lourenço do Rosário analisa esta obra sintetizando o romance como sendo expressão da luta de Rami para libertar-se emocionalmente e financeiramente de seu marido. Mas, seguindo a perspectiva de Simone de Beauvoir, a mulher se emanciparia quando conquistasse autonomia financeira e quando pudesse controlar a concepção, evitando, assim, transformar sua existência em função da criação dos filhos. Rami casa-se com Levy, seu cunhado, porque engravidou no kutchinga. Por isso, ela está fadada a entrar em um outro casamento poligâmico. Podemos inserir os dois romances como pertencentes à mesma corrente literária feminina africana que, como vimos, problematiza a necessidade de ter uma presença masculina no lar, o direito à herança em caso de morte 
do cônjuge poligâmico e, consequentemente, a autonomia financeira feminina na sociedade africana contemporânea. Seriam esses romances exemplos de narrativas de vidas femininas descrevendo seus processos de tomada de consciência de seus gêneros?

Por ocupar uma posição secundária na sociedade, a temática feminina é estudada pela mesma lógica que rege os estudos de todos aqueles que não cumpririam os requisitos do modelo idealizado pelo eurocentrismo: nascer homem branco e ser economicamente ativo. Ao excluir esse tipo privilegiado, tem-se a representação de personagens excluídas do campo de poder. Mas, além de serem mulheres e, segundo Beauvoir (1970), representar o Outro, as personagens tratadas estão inseridas em dois contextos sociais nos quais as mulheres ainda não se emanciparam economicamente. Entretanto, a autonomia financeira feminina seria influência direta para o fim do patriarcalismo? Como o sistema capitalista se apropria do patriarcalismo em seu funcionamento?

Ao longo dos anos, a luta das mulheres africanas tem mudado a realidade feminina em algumas partes do continente. Primeiro, pela produção de romances por autoras que problematizam a temática feminina. Segundo, por organizações sociais que promovem mudanças junto à sociedade, como o fim da excisão em meninas. E, terceiro, pela participação de mulheres preocupadas com esses temas no campo de poder, possibilitando ações e políticas públicas para as mulheres, ou a mudança de leis, como o reconhecimento do direito feminino à posse da terra e à hereditariedade.

\section{BIBLIOGRAFIA}

BÂ, M. Une si longue lettre. 2014 (collectionMotifs)

BEAUVOIR, S. O Segundo Sexo: Fatos e Mitos. $4^{\mathrm{a}}$ edição. São Paulo: Difel, 1970. (vol.I).

. O Segundo Sexo: A Experiência Vivida. $3^{\text {a }}$ edição. São Paulo: Difel, 1967. (vol. II).

BOURDIEU. A dominação masculina.

CHIZIANE, P. Niketche: uma história de poligamia. Lisboa: Caminho, 2002.

FAINZANG, S.; JOURNET, O. La femme de mon mari: Anthropologie du mariage polygamique em Afrique et en France. Paris: Harmattan, 1988. 
MARINA BUENO DE CARVALHO A poligamia em Une si longue lettre e Niketche: uma história de poligamia

KI-ZERBO, J. História da África Negra. Paris: Hatier, 1972. v.1.

SENEGAL e Burkina Faso. Práticas tradicionais do casamento como determinantes dos direitos agrários da mulher: análise de pesquisas. In: Compêndio de estudos de países sobre gênero e terra. Disponível em: < http://www.fao.org/docrep/010/a0297p/a0297p00.htm>. Acesso em: 21 fev. 2016.

SERRANO, C.; MUNANGA, K. A Revolta dos Colonizados: O processo de descolonização e as independências da África e da Ásia. São Paulo: atual, 1995.

SOW, F. S. Famille et loi au Sénégal: permanences et changements. Programe Femmes et loi dans le monde musulman. Dossier special. Les frontiers mouvantes du marriage et du divorce dans les communités musulmanes. 1996.

SOW, Fatou; BOP, Codou. Notre corps, notre santé: La santé et la sexualité des femmes en Afrique subsaharienne. Paris: L'Harmattan, 2004. 